A $R$ R T TÍl C U U L

$\begin{array}{lllllllll}R & E & F & L & E & X & I & O & N\end{array}$

\title{
El RACISMO FOUCAULTIANO COMO HERRAMIENTA ANALÍTICA PARA EL DEBATE POLÍTICO CONTEMPORÁNEO
}

FOUCAULDIAN RACISM AS AN ANALYTICAL TOOL FOR CONTEMPORARY POLITICAL DEBATE

Por: Carlos Mario Herrera Casadiego*

* Candidato a magíster en Ciencia Política de la Universidad de los Andes, Colombia. Filósofo egresado del programa de Filosofía de la Universidad de Cartagena, Colombia. Investigador en las líneas temáticas

de filosofía política, ciencia política, violencia y conflicto armado.

\section{RESUMEN}

A partir de una revisión de la obra de Michel Foucault, el presente artículo se propone evidenciar cómo el concepto de racismo formulado por el filósofo francés puede emplearse como herramienta analítica para el debate político contemporáneo. En el transcurso del cumplimiento de ese propósito se pondrán de relieve los rasgos principales de los tres paradigmas de poder expuestos por Foucault, estos son: soberano, disciplinario y biopolítico. Esta exposición servirá como marco de referencia para introducir el concepto de racismo, definir sus características y operatividad, así como mostrar casos en los que la categoría puede ser instrumento de análisis para fenómenos políticos concretos.

Palabras clave: Racismo, Soberanía, Disciplina, Biopolítica, Poder.

\begin{abstract}
Based on a review of the work of Michel Foucault, this article aims to show how the concept of racism formulated by the French philosopher can be used as an analytical tool for contemporary political debate. To fulfill this purpose, the main features of the three power paradigms exposed by Foucault will be highlighted: sovereign, disciplinary and biopolitical. This work will serve as a frame of reference to introduce the concept of racism, to define its characteristics and operability, as well as to show cases in which the category can be an instrument of analysis for concrete political phenomena.
\end{abstract}

Keywords: Racism, Sovereignty, Discipline, Biopolitics, Power.

\section{Consideraciones preliminares}

ichel Foucault desde su obra temprana, precisamente desde
Historia de la locura en la época clásica, y durante su estancia como
profesor del Collége de France desde 1971 hasta 1984, el año de su muerte, se interesó por el análisis del poder y sus mecanismos de operación, un asunto transversal en toda su obra. Pero no se trata de un Poder -así, con mayúscula- homogéneo, atribuible a una clase social, que se pueda poseer o 
tenga un origen fijo e identificable en la historia; Foucault funda una nueva perspectiva y define un poder que se ejerce y es heterogéneo, un poder que se ejecuta en red, a través de relaciones de variada intensidad, un poder que está en continua transformación.

Aunque tradicionalmente el poder fue considerado como ese componente jurídico que determina lo que debe ser prohibido o no, o como las fuerzas que discurren por la vía legalista, Foucault va un poco más allá y analiza elementos extrajurídicos, aquellos que históricamente han operado sobre los individuos y el cuerpo social y exceden el ámbito del derecho. Bajo la mirada foucaultiana el poder no se ejerce por una sola vía a través del aparato jurídico legal, hay numerosos mecanismos, así como relaciones de poder, que pueden ser utilizadas y aprovechadas por un grupo social para ejercer dominación sobre otro. Aquí es necesaria una precisión: son utilizadas mas no son propiedad exclusiva de ese cuerpo social que puede usarlas de manera deliberada o no. Así, las relaciones de poder ejecutadas en red, o bien el uso efectivo de esas relaciones, posibilitan la dominación de un grupo social sobre otro. El poder es el que ejerce el Estado sobre los ciudadanos pero también está presente en instituciones como la familia, la escuela o el hospital.

En el transcurso de su analítica del poder Foucault se pregunta sobre el trasfondo que subyace a las relaciones de poder. ¿Hay una especie de guerra incesante bajo el orden instaurado por las relaciones de poder?, es la pregunta que inicialmente plantea. En suma, lo que ocupa el interés de Foucault es una sentencia cuyo origen se remonta a los siglos XVII y XVIII en Europa pero que comúnmente se le conoce como la inversión del aforismo de Clausewitz y que dice así: "la política es la continuación de la guerra por otros medios". Sostiene Foucault que de la mano del crecimiento y consolidación de los Estados durante la Edad Media, la guerra entendida como práctica política sufrió una transformación representada en un paulatino desplazamiento de su ámbito de acción. Lo bélico pasó a ser competencia del Estado que para las nuevas funciones creó una institución, un aparato militar: el ejército. En este nuevo escenario solo el Estado estaba facultado para librar guerras, pero solo podía hacerlo más allá de sus límites territoriales y en el marco de disputas con otros Estados.

Paralelo a la transformación mencionada, luego de las guerras civiles y religiosas del siglo XVI en Europa, del derrumbe paulatino del poder real, y de las luchas populares a finales del mismo siglo, emerge un nuevo discurso que se 
ocupará de la guerra en tanto que relación social; se trata del "primer discurso histórico político sobre la sociedad" (Foucault, 2001: 54). En síntesis, este discurso sostiene que el poder político no comienza tras el fin de la guerra, si bien los conflictos bélicos precedieron el nacimiento del Estado y las leyes, "eso no quiere decir que la sociedad, la ley y el Estado sean como el armisticio de esas guerras o la sanción definitiva de las victorias" (Foucault, 2001: 56). La guerra, entonces, pervive latente en las entrañas del cuerpo social, en este nuevo escenario el orden establecido ya no será jerárquico, piramidal o ternario como lo sugerían las teorías filosófico-políticas de la Edad Media sino que hay dos grupos de individuos en plena contienda. Se trata de un discurso que fungió como herramienta política de emancipaciones populares, un discurso contestatario y beligerante, aunque no de uso exclusivo porque fue utilizado por diversos actores.

El individuo que emite ese discurso se aleja de la posición neutral del sujeto universal, es el individuo que lucha por sus derechos pero con una particularidad: "[son] derechos singulares, fuertemente marcados por una relación de propiedad, de conquistas, de victoria, de naturaleza. Será el derecho de su familia o su raza, el de su superioridad..." (Foucault, 2001: 57). En ese sentido, lo que subyace a la guerra social es la guerra de razas, una guerra fundamentada por un variado conjunto de diferencias de tipo lingüístico, étnico, cultural, etc., arraigadas profundamente en el cuerpo social, una guerra que ha tenido transcripciones o ejemplificaciones concretas en la historia.

Para Foucault, aquí cabe hacer la aclaración, raza alude a un grupo social que no comparte origen, lengua o religión con otro; razas, o en aras de una comprensión más precisa: etnias, son dos grupos que si llegaren a convivir la unidad de esa convivencia estaría sostenida sobre la base de la violencia. Así, "hay dos razas cuando hay dos grupos que, pese a su cohabitación, no están mezclados a causa de diferencias, disimetrías, barreras debidas a los privilegios, las costumbres y los derechos, la distribución de las fortunas y el modo de ejercicio del poder" (Foucault, 2001: 77).

Foucault, de igual manera, identifica lo que denomina transcripciones del discurso de la lucha de razas: por una parte, se encuentra una transformación de ese discurso en clave de lucha de clases que será herramienta de luchas y reivindicaciones populares. Por otro lado, se encuentra una transcripción en términos biológicos, se trata de una idea que determinará un cambio de enfoque, un viraje en la operatividad del discurso mismo: no habrá más una 
disputa intestina entre dos razas sino que una raza buscará imponerse sobre otra, el discurso ahora será "de un combate que no debe librarse entre dos razas, sino a partir de una raza dada como la verdadera y la única (...) contra los que se desvían de ella, contra los que constituyen otros tantos peligros para el patrimonio biológico" (Foucault, 2001: 65).

La teoría de la guerra de razas ya no será funcional a luchas políticas emprendidas de una raza contra otra sino que se convertirá en un discurso racista que opera como criterio de doble aplicación: i) como eliminación o muerte física y ii) como exclusión, marginación o muerte política. El foco de discurso tiene ahora un matiz biológico y evolucionista, será instrumentalizado por el Estado para mantener la pureza de la raza, de la sociedad, aquí el Estado opera como salvaguarda de una sociedad biológicamente monista que debe repeler aquellos elementos ajenos a su esencia. Surge así el racismo de Estado, un concepto de gran relevancia en el pensamiento foucaultiano. Pero, ¿̇cómo opera el racismo? , ¿cómo tejió Foucault el hilo argumentativo que daría lugar al surgimiento del racismo como categoría filosófica? En adelante se verá.

Para comprender cómo el racismo es instrumentalizado por el Estado es necesario primero conocer la dinámica de operación de las tecnologías de poder expuestas por Foucault, las cuales sirven a su vez como marco de referencia a los propósitos centrales del presente artículo. Así pues, para Foucault el poder soberano podía ejercer el derecho de vida y muerte sobre sus súbditos: si se presentaba una causa legítima el monarca podía disponer de la vida de sus súbditos y enviarlos a la guerra, es decir, exponerlos ante la muerte; o bien si se rebelaban en su contra podía matarlos. El derecho soberano de vida y muerte se puede expresar bajo la fórmula hacer morir o dejar vivir (Foucault, 1998: 163).

No obstante, los mecanismos de poder que sustentaban ese derecho soberano de vida y muerte sufrieron una profunda transformación. El poder soberano perdió su rol primordial y fue sustituido por el biopoder, un poder que se ejerce sobre la vida y sus accidentes biológicos, que se propone controlar la vida en detalle. Los individuos ya no tienen un soberano que defender por el cual serían enviados a la guerra, bajo este nuevo poder las guerras serán invocadas en nombre de la población, de la supervivencia de todos. Bajo el biopoder se pasará del hacer morir o dejar vivir del poder soberano a hacer vivir y dejar morir (Foucault, 1998: 167). 
En ese sentido, es necesario poner de relieve los rasgos principales de los tres paradigmas de poder expuestos por Foucault, estos son: soberano, disciplinario y biopolítico. De igual manera, se expondrá en qué consisten las transformaciones en las tecnologías de poder señaladas por Foucault y cómo tuvieron lugar las transiciones entre un paradigma y otro. Todo con miras a comprender a cabalidad la dinámica de operación del racismo y la posible utilidad del concepto como herramienta analítica para el debate político contemporáneo.

\section{Poder soberano, hacer morir o dejar vivir}

1 loucault rastrea el origen del poder soberano en la gestación y conformación del pensamiento jurídico de Occidente durante la Edad Media. Hay un hecho que marca el surgimiento de la soberanía como problema político, se trata de la caída del Imperio Romano que trajo consigo la disolución de todo el entramado jurídico de Occidente; luego de ese momento histórico el derecho tuvo que reiniciar su actividad por lo que cumplió un rol importante en la posterior constitución de la teoría jurídico política de la soberanía y, por ende, del poder monárquico. El derecho fue "uno de los instrumentos técnicos constitutivos del poder monárquico, autoritario, administrativo y, finalmente, absoluto" (Foucault, 2001: 35). Es así como derecho y soberanía estuvieron estrechamente vinculados en una suerte de simbiosis.

En ese sentido, es necesario destacar cuatro roles que el derecho en tanto que teoría jurídico-política de la soberanía interpretó en su desarrollo histórico: en un primer momento "se refirió a un mecanismo de poder efectivo que era el de la monarquía feudal" (Foucault, 2001: 42). Asimismo, las monarquías administrativas de la época encontraron en la teoría soberana un instrumento útil y el basamento sobre el cual fundamentarse. De igual manera, el aparato jurídico de la soberanía ofició como herramienta usada indistintamente en dos sentidos: ya sea para limitar o para robustecer el poder del soberano, "fue el gran instrumento de la lucha política y teórica alrededor de los sistemas de poder de los siglos XVI y XVIII" (Foucault, 2001: 43). Y por último, fue elemento fundacional de las democracias parlamentarias entendidas como relevo alternativo a las monarquías administrativas, un papel que desempeñó activamente durante la Revolución Francesa.

Los roles descritos evidencian que durante la sociedad feudal el poder soberano abarcó en términos generales la dinámica del poder, se ocupó en detalle de la mecánica de poder resultante de la relación establecida entre el soberano y el 
súbdito. En suma, en las sociedades occidentales el derecho, el sistema jurídico en general, se construyó a partir y alrededor del poder real, sobre la base de la figura del soberano como eje central de la vida política. El derecho se creó para que fuera un elemento funcional al ejercicio del poder soberano, para que operara como herramienta y justificación del poder del monarca; fue la respuesta a un pedido del soberano.

El poder soberano no se agota en su relación con el derecho. Es necesario destacar también la relación entre el soberano y los individuos, es decir, los sirvientes o súbditos, - pues no hay otro tipo de relación entre ellos - , la cual está mediada por el sometimiento y la obediencia; la voluntad del monarca es inquebrantable so pena de muerte. En suma, para Foucault, como lo sostiene en El poder psiquiátrico (2007), la soberanía es una relación de poder que une o vincula al soberano y al súbdito bajo dos relaciones asimétricas: la sustracción y el gasto. El soberano sustrae diversos elementos de los siervos como el tiempo y el servicio, la fuerza de trabajo y los productos de la misma; y en retribución, el soberano a través del gasto debe devolver lo que tomó prestado expresado en elementos como las ceremonias rituales religiosas, festivas, o la protección militar. No obstante, la sustracción siempre es superior al gasto $y$, por tal motivo, la relación establecida entre el monarca y los individuos sometidos a su voluntad es desequilibrada, disimétrica (Foucault, 2007).

En las relaciones de soberanía el poder no se detiene en un cuerpo individual concreto porque interviene sobre una multiplicidad que excede lo individual, actúa sobre cuerpos colectivos como la familia. Lo que sí está asegurada es la individualidad del rey pues al cuerpo del soberano es hacia donde convergen todas las relaciones implicadas en las relaciones de soberanía. El monarca, ante la ausencia de individualidades concretas, se instituye como punto de fuga de las relaciones de poder en la soberanía. Sin embargo, es necesario que esa singularidad instituida en el soberano no desaparezca con la muerte física del rey, debe permanecer para que se mantenga la monarquía pues es el cuerpo del soberano el que mantiene unidas las relaciones de soberanía. Así que el cuerpo del rey es doble o múltiple, se conforma una dualidad en la que hay un elemento perecedero y otro que trasciende en el tiempo (Foucault, 2007: 65).

Ahora, para que el soberano pudiera ejercer su derecho de vida y muerte sobre los súbditos necesitaba de una herramienta, de un instrumento de dominación: la ley. La forma de ley soberana que imperó en la Edad Media hasta el siglo XVIII, Foucault la define de la siguiente manera: 
[Se trata de] sancionar una ley y fijar un castigo a quien la infrinja, es el sistema del código legal con partición binaria entre lo permitido y lo vedado y un acoplamiento que es justamente el meollo del código, entre un tipo de acción prohibida y un tipo de castigo. Se trata del mecanismo legal o jurídico (Foucault, 2006: 20).

En ese sentido, el derecho, expresado en la ley penal o en las instituciones que aplican la ley e imponen castigos, establece las relaciones de dominación en las sociedades de la época. Las leyes son transcripciones de la voluntad del soberano y no se pueden incumplir a riesgo de muerte o castigos severos. Como lo sostiene Hall (2007): "In pre-modern society, laws were considered to be direct extensions of the sovereign's will, thus in breaking those laws one not only violated the immediate victim, but personally assaulted the sovereign himself" (pp. 10). En resumen, el soberano en ejercicio de su poder, como epicentro de la vida política, poseía el derecho de vida y de muerte sobre sus súbditos, tenía la potestad de hacer morir o dejar vivir. Un derecho indirecto o de réplica en tanto que es efectivo cuando la persona del rey estaba en peligro, cuando había un peligro externo. Además, es un derecho que provenía de: "la vieja patria potestad que daba al padre de familia romano el derecho de "disponer" de la vida de sus hijos como de la de sus esclavos; la había 'dado', podía quitarla" (Foucault, 1998: 163).

Lo anterior implica que vida y muerte se desnaturalizan, dejan de ser fenómenos naturales y se convierten en elementos dependientes de la voluntad del soberano. El siervo se encuentra en un espacio de neutralidad, ante el poder no está vivo o muerto (Foucault, 2001: 218). Si un súbdito osaba cuestionar la voluntad del soberano, este de manera legítima podía acabar con su vida. En palabras del pensador francés: "la vida y la muerte de los súbditos sólo se convierten en derechos por efecto de la voluntad soberana" (Foucault, 2001: 218). En ese sentido, el derecho de vida y muerte en el marco del poder soberano se ejerce primordialmente desde el lado de la muerte. Es decir, "el soberano no ejerce su derecho sobre la vida sino poniendo en acción su derecho de matar, o reteniéndolo, no indica su poder sobre la vida sino en virtud de la muerte que puede exigir" (Foucault, 2001: 163).

\section{Poder disciplinario, un poder incesante que se abate sobre el cuerpo}

7 i con un hecho histórico Foucault ilustró el origen del poder soberano, de nuevo recurre a la historia para representar el tránsito del paradigma soberano al paradigma disciplinario del poder. El autor narra en El 
poder psiquiátrico (2007) lo ocurrido al rey Jorge III de Inglaterra que sumido en la manía fue internado y aislado en un palacio con el fin de ser tratado. Las paredes internas de su habitación fueron recubiertas con colchones para evitar que se lastimara. En ese punto, al momento de ser internado, el médico encargado del tratamiento curativo del monarca le informa que había dejado de ser rey y debía mostrarse sumiso y dócil ante cualquier petición que el proceso requiera. Dos de sus antiguos sirvientes se encargaban de sus cuidados y a la vez le recordaban que debía ser obediente, y cuando la situación lo ameritaba hacían uso de su fuerza y superioridad para controlarlo.

Foucault expone el caso del rey Jorge III porque evidenció un punto de inflexión, el paso de un poder a otro. El rey Jorge III al momento de ser recluido dejó de ser soberano a través de "una ceremonia de destitución, una especie de coronación al revés en la cual se indica con mucha claridad que se trata de poner al rey bajo una dependencia total" (Foucault, 2007: 37). Se trata de un ritual en el que el rey perdió sus facultades, quedó aislado, reducido, disfuncional, inerme. En ese nuevo escenario, el rey postrado y despojado de sus poderes quedó a merced de un nuevo poder, con nuevas características, de agenciamiento múltiple pero invisible.

Es así como entre los siglos XVII y XVIII empezó a despuntar una nueva dinámica de poder que no se regía por la relación entre soberano y súbdito sino que se centró en el cuerpo de los individuos. Se trató del poder disciplinario, un nuevo poder que contrarresta la primacía del soberano en favor de una serie de obligaciones y normas, y que se ejerce primordialmente a través de la vigilancia continua, incesante. Aunque el poder disciplinario no tuvo un origen específico en la historia, es posible rastrear su emergencia en las comunidades religiosas de la Edad Media que luego darían paso a las comunidades laicas durante los siglos XIV y XV en los que el poder disciplinario se desarrollaría. Foucault destaca a la comunidad laica llamada Hermanos de la Vida Común, surgida en tierras neerlandesas durante el siglo XIV, como una de las primeras representantes del poder disciplinario puesto que tomaron técnicas y ejercicios ascéticos de la vida conventual y la tradición religiosa para desarrollar métodos disciplinarios aplicables a la vida cotidiana (Foucault, 2007: 60).

Los dispositivos disciplinarios se integraron al esquema general de la soberanía feudal y monárquica en la Edad Media en los siglos XVII y XVIII; previo a su consolidación ya estaban inscritos en el seno del poder soberano, aunque operaban de manera aislada pues actuaban como contrapeso, como elemen- 
to crítico opositor. Posteriormente, hubo una paulatina masificación de los dispositivos disciplinarios en el cuerpo social, una "extensión progresiva o parasitación general" (Foucault, 2007: 87) del poder disciplinario en la sociedad como se hizo evidente en ámbitos como la escuela con la disciplinarización de la juventud estudiantil o con los esquemas disciplinarios aplicados a las poblaciones colonizadas que operaron en oposición a la esclavitud. Un ejemplo de esto último fueron los jesuitas en Sudamérica que implementaron un sistema de vigilancia permanente, una penalidad de los castigos y toda suerte de mecanismos disciplinarios en sustitución del sistema explotador esclavista (Foucault, 2007: 90).

Ahora bien, ¿qué hay detrás de esa extensión progresiva o generalización de los dispositivos disciplinarios? La respuesta es la "acumulación de los hombres" (Foucault, 2007: 94), es decir, la distribución de la fuerza de trabajo de manera simultánea a la acumulación del capital, un pilar en el desarrollo del capitalismo. En detalle, se buscaba hacer útil a la totalidad de los individuos, maximizar y optimizar al extremo su capacidad de producción. La disciplina oficiaba como una táctica de distribución de los individuos que sustituía la taxonomía clasificatoria de las ciencias clásicas (Foucault, 2007: 83).

Como se ha visto hasta el momento la disciplina es una mecánica de poder distinta a la soberanía pero que, como se expondrá, pudo convivir con ella. A pesar de la irrupción del poder disciplinario el discurso jurídico de la soberanía no desapareció sino que sobrevivió imbricado al discurso normalizador de la disciplina. Es posible establecer una distinción clara entre los dos paradigmas hasta el momento abordados, la diferencia reside principalmente en las formas en las que se manifiesta cada uno de ellos. Mientras que en el poder soberano un solo individuo ejerce el poder y monopoliza la fuerza; el poder disciplinario es un poder repartido en red, que se ejecuta en silencio y solo es visible en la medida en que los individuos sobre los que se ejerce son dóciles y sumisos. Es el paso de la macrofísica del poder soberano a la microfísica del poder disciplinario.

Por otra parte, la disciplina se puede contraponer a la soberanía porque en ella no está presente la relación de sustracción y gasto entre el monarca y sus súbditos, no existe la asimetría y el desequilibro manifiestos en las relaciones de soberanía. En el caso del poder disciplinario, no hay sustracciones parciales del producto o los servicios sino que hay una aprehensión total del cuerpo. Para Foucault (2007) "todo sistema disciplinario (...) tiende a ser una 
ocupación del tiempo, la vida y el cuerpo del individuo" (p.67). Y ejemplo de esto último es la disciplina militar que surge a finales del siglo XVII y confina al individuo hasta que muere en un riguroso esquema que se apodera de su tiempo y de su cuerpo.

Otro aspecto del sistema disciplinario que se contrapone al poder soberano es el referido al procedimiento. Mientras que en las relaciones de soberanía hay un juego discontinuo y ceremonial marcado por una diversidad de rituales aplicados, por ejemplo, por el soberano para ejercer su derecho de muerte, el poder disciplinario se caracteriza por ejercer un control continuo que nunca acaba sobre los individuos con miras a un "estado terminal u óptimo" (Foucault, 2007: 67) donde la disciplina sea plenamente asimilada a tal punto que su accionar se invisibilice. Y es ese ejercicio constante el que garantiza, en efecto, el perpetuo funcionamiento del poder disciplinario.

En suma, desde el siglo XIX en las sociedades modernas conviven los dos paradigmas de poder, sin superponerse, manteniendo las particularidades de sus discursos, en una marcada relación heterogénea. Durante la Edad Media el poder disciplinario surge y luego evoluciona hasta alcanzar su punto de consolidación y formulación política más concreta expresada en El panóptico de Bentham de 1791. A partir de allí el poder disciplinario conforma una "forma social absolutamente generalizada" (Foucault, 2007: 61) de tal manera que se puede hablar tanto de sociedad disciplinaria como de sociedad panóptica. Curiosamente, la publicación de El panóptico de Bentham coincide en la historia con el suceso antes narrado del Rey Jorge III.

El ejemplo del panóptico es adecuado para introducir lo concerniente al individuo en el marco del poder disciplinario. Para iniciar, es preciso conocer la estructura física del panóptico que Foucault en El poder psiquiátrico describe de la siguiente manera:

Tenemos un edificio anular que constituye la periferia misma del panóptico: en él se disponen celdas que se abren a la vez hacia el interior por una puerta vidriera y hacia el exterior por una ventana. En el contorno interno de ese anillo tenemos una galería que permite circular e ir de una celda a otra. A continuación, un espacio vacío y, en su centro, una torre, una especie de construcción cilíndrica de varios pisos y en cuya cima hay una linterna, es decir, una gran habitación vacía con una estructura tal que, con sólo girar sobre sí mismo, un observador puede mirar desde ese

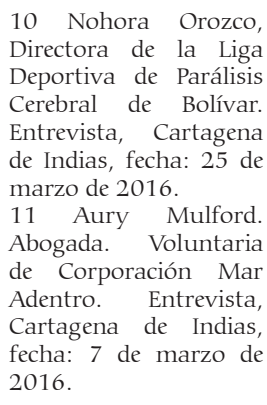
Deportiva de Parálisis Cerebral de Bolívar. Entrevista, Cartagena de Indias, fecha: 25 de marzo de 2016.

11 Aury Mulford Abogada. Voluntaria de Corporación Mar Adentro. Entrevista, Cartagena de Indias, fecha: 7 de marzo de 2016 
emplazamiento central todo lo que ocurre en cada una de las celdas. Ése es el esquema (Foucault, 2007: 98).

En el panóptico es posible ver representada la mecánica general del poder disciplinario y con mucho más énfasis la función individualizadora de la disciplina. Bajo ese sistema solo una persona ocupará cada celda de reclusión y quien oficie como vigilante del recinto solo podrá, independientemente del lugar hacia donde dirija su mirada, ver a un solo individuo. Es decir, en el panóptico no existen las colectividades, desaparece el problema de las multiplicidades; las órdenes serán recibidas por individuos aislados, segregados.

La disciplina busca individualizar los cuerpos de los sujetos sobre los que opera, aunque desde el punto del cual se ejerce sea un poder colectivo en tanto que, en el caso del panóptico, cualquiera puede acceder y vigilar desde la torre central de vigilancia. Se configura así lo que Foucault denomina democratización del ejercicio del poder disciplinario. Sin embargo, la disciplina del panóptico no solo individualiza sino que también permite conocer a los individuos vigilados en tanto que opera también como mecanismo de saber. Lo logra a través de la escritura como herramienta codificadora de la vida de los individuos recluidos. Se busca registrar en detalle el progreso del individuo, se quiere transcribir su individualidad. En suma, el panóptico se trata de: "un esquema formal para la constitución de un poder individualizador y un saber sobre los individuos. (...) [Un] poder ejercido sobre el hombre en cuanto fuerza de trabajo y el saber sobre el hombre en cuanto individuo" (Foucault, 2007: 103). Es un esquema que en su mecánica general luego podrá verse replicado en instituciones como la escuela, el hospital o los cuarteles de instrucción militar.

Ahora, así como el soberano necesitaba de una herramienta de dominación ejemplificada en la ley, la disciplina hizo uso de la norma para ejercer su dominio. La disciplina establece la norma, opera bajo la dinámica binaria de lo permitido y lo prohibido, en ese sentido es prescriptiva, es decir, dictamina qué es lo obligatorio. Para Foucault, en el marco de la disciplina se le da mayor importancia a lo que está prohibido porque el objetivo será lograr el orden luego de anular lo negativo. En sus palabras: "El orden, en efecto, es lo que queda una vez que se ha impedido todo lo que está prohibido" (Foucault, 2006: 68). En ese sentido, el discurso disciplinario se aleja de la ley emanada de la soberanía. El nuevo discurso de la disciplina, entonces, es el de la norma en tanto que código normalizador, se establece la norma porque es la encargada 
de los procedimientos de control y adiestramiento, se elabora un modelo, un prototipo a seguir, esto es, la norma a la que los individuos deben ajustarse. Quien no la cumpla, así suene redundante, es el anormal y quien la cumpla es normal. La norma surge como consecuencia de la necesidad del poder por adecuarse a las nuevas demandas políticas de la sociedad, cimenta las bases de lo que será una nueva técnica de poder que se ocupe enteramente de la vida y de la muerte, y asimismo del individuo como miembro constitutivo de una especie.

\section{Poder biopolítico, hacer vivir y dejar morir}

7 partir del siglo XIX en las sociedades occidentales modernas la vida empieza a ser abordada por el poder, en palabras de Foucault (2001): 1 _....) el poder, en el siglo XIX, tomó posesión de la vida” (p. 229); surge el interés del poder político por el ámbito biológico, por el hombre en tanto que ser viviente y miembro constitutivo de una especie. Así, aparece una tecnología de poder que integra a las anteriores, una tecnología que cambia de objetivo y se ocupa del hombre como ser biológico. A partir de ese reconocimiento es posible entender el surgimiento de lo que Foucault denomina el biopoder, el cual define como: "El conjunto de mecanismos por medio de los cuales aquello que, en la especie humana, constituye sus rasgos biológicos fundamentales podrá ser parte de una política, de una estrategia política, una estrategia general del poder" (Foucault, 2006: 15). Es un tipo de poder que se ocupa de la vida en su generalidad, actúa sobre dos focos de incidencia: el cuerpo y la población.

El fin de la nueva tecnología de poder llamada biopolítica, que usa como herramienta al biopoder, es la optimización de un estado de la vida. Con base en el acervo estadístico, codificado previamente a través de dispositivos disciplinarios como la escritura, se busca intervenir a través de mecanismos globales en los fenómenos, igualmente globales, que se presentan en la población con miras a lograr un equilibrio continuamente regulado. En suma, ya no se busca obtener una disciplina de los cuerpos individuales sino la regularización de la población, el equilibrio global, un estado denominado homeostasis, esto es, "la seguridad del conjunto respecto a sus peligros internos" (Foucault, 2001: 226).

Si la mirada del poder político se desplazó hacia otro objetivo y surgieron nuevas exigencias también fue necesario que se transformaran sus mecanismos de operación, fue indispensable que se adaptaran a los fenómenos 
poblacionales, globales, y eso fue posible gracias a lo que Foucault llama mecanismos de seguridad, que a su vez son la respuesta a un problema de empatía entre la ciudad y la soberanía, son la respuesta a la pregunta: “¿Cómo ejercer la soberanía sobre la ciudad?" (Foucault, 2006: 85). Los mecanismos de seguridad además de englobar los elementos del orden jurídico-legal y disciplinario inscriben el delito en una "serie de acontecimientos probables" (Foucault, 2006: 21) con dos referentes definidos: la relación costo-beneficio en términos sociales o económicos y la media estadística de criminalidad asumida como aceptable.

En ese sentido, los dispositivos de seguridad se ocupan de manera distinta de los fenómenos que inciden en la población, modifican el enfoque: ya no buscan anular el fenómeno distinguiendo lo normal de lo anormal, lo enfermo de lo no enfermo como lo hacía la disciplina sino que se proponen controlarlo como conjunto unitario sobre la base de la probabilidad. Es decir, hay un abordaje distinto de los fenómenos, lo que busca la biopolítica es situarlos dentro de un límite aceptable para la población en lugar de prohibirlos o vetarlos. La seguridad propone una alternativa al eje de poder establecido entre soberanos y súbditos, por tal motivo se aleja de promulgar prohibiciones de los fenómenos. Además, la seguridad, en el ejercicio de su operatividad, emplea una serie de elementos teóricos como lo es la noción de caso, referida a la individualización de los fenómenos colectivos, esto quiere decir, desvincular los fenómenos de caracterizaciones globales; ya no se abordará, por ejemplo, una enfermedad como un fenómeno relacionado con un país o ciudad sino que se analizará como un caso específico y particular. Y por la misma vía, a través de la noción de caso se pueden colectivizar los fenómenos individuales, es decir, inscribirlos en un ámbito global susceptible de ser analizado.

Otro elemento teórico usado por la seguridad es la noción de riesgo: riesgo de contagio de una enfermedad, por ejemplo. El riesgo no es una noción fija, presenta gradaciones, no es el mismo nivel de riesgo al que todos los individuos están expuestos por lo que también se hace necesario establecer el nivel de peligrosidad. Y, por último, la intensidad con la que se presenta el fenómeno no es estable, habrá momentos de alta intensidad por lo que es relevante identificar los momentos de crisis. En resumen, son cuatro las nociones teóricas que introduce la seguridad, a saber: caso, riesgo, peligro y crisis.

Ahora, la biopolítica también necesita una herramienta operativa, en este caso debe abarcar dos ámbitos: el cuerpo-individuo y la especie. Desde una 
perspectiva más amplia la noción de norma atraviesa esos dos ámbitos. Si bien para Foucault inicialmente la norma hacía referencia a la disciplina y a la sociedad de normalización entendida como aquella sociedad plagada de instituciones disciplinarias, a su juicio esa visión no es satisfactoria. La sociedad de normalización, regulada por la norma, es "una sociedad donde se cruzan, según una articulación ortogonal, la norma de la disciplina y la norma de la regularización" (Foucault, 2001: 229).

En suma, a partir del interés ya descrito del poder sobre la vida es posible evidenciar la transformación de las tecnologías de poder. Si en el marco del poder soberano la fórmula consistía en hacer morir o dejar vivir, bajo el biopoder, la fórmula se invierte y pasa a hacer vivir y dejar morir. Esta inversión de la fórmula, y el biopoder mismo, se manifiestan en la "descalificación progresiva de la muerte" (Foucault, 2001: 224). Es decir, la muerte pasó de ser un fenómeno público, ataviado de una ceremonia y un ritual, espectacular, en el sentido más literal del término; a convertirse en un hecho privado que debe ser ocultado.

Ese cambio progresivo de la muerte es el reflejo de una transformación más profunda de las tecnologías de poder. A finales del siglo XVIII la muerte era un punto de inflexión, simbolizaba el cambio de un poder a otro, la sustitución de una competencia terrenal por una divina: el súbdito pasaba de manos del monarca de la tierra, del rey, a manos del soberano divino, Dios (Foucault, 2001: 224). Luego, con la irrupción del biopoder habrá un viraje, un cambio, se diluye el derecho de hacer morir y se convierte paulatinamente en un derecho para hacer vivir a través de una intervención sobre la vida, para regular y controlar sus riesgos y accidentes, convirtiéndose la muerte en el límite del poder. En ese sentido el poder solo ejerce incidencia sobre un campo estadístico, externo a la vida misma, por lo que se sigue que la muerte se desplaza a un lugar privado, cada vez más íntimo y oculto. Es decir, en este nuevo ámbito: "El poder ya no conoce la muerte. En sentido estricto la abandona" (Foucault, 2001: 225). La pregunta que surge es cómo la biopolítica puede ejercer el derecho de muerte si su énfasis está ceñido a la vida y sus aspectos biológicos. En suma, “icómo puede matar un poder como ése, si es verdad que se trata esencialmente de realzar la vida, prolongar su duración, multiplicar sus oportunidades, apartar de ellos accidentes o bien compensar sus déficits?" (Foucault, 2001: 230). 


\section{Conclusiones}

Tr a interpretación tradicional de la analítica del poder de Foucault ha confinado a la muerte en un lugar secundario, como una simple eventualidad ineludible. La muerte ha sido entendida como un aspecto de la vida sobre el cual no interviene la biopolítica. Contrario a la tendencia generalizada, autoras como López ponen de relieve el ejercicio thanático de la biopolítica con el propósito de ponderar el abordarje de la muerte en el marco del paradigma biopolítico, es decir, busca desentrañar "los alcances mortíferos del dispositivo [biopolítico] y del estatuto y del rol que se le asigna a la muerte en este contexto" (López, 2013: 70).

Foucault, sin embargo, en Defender la sociedad aclara que la biopolítica también se interesa por la muerte, el dispositivo biopolítico entraña una profunda "lógica mortífera" (López, 2013: 82) expresada en el racismo. Para el filósofo francés, el racismo es la herramienta que puede usar el poder biopolítico para ejercer el derecho de dar muerte, es el recurso soberano que usa la biopolítica para convertir el dejar morir en "acto de hacer morir" (López, 2013: 79).

Así pues, el racismo en el marco de la biopolítica tiene unas funciones claramente definidas. Primero, se va a encargar de segmentar lo que Foucault denomina el continuum biológico de la especie humana. El racismo segmenta lo biológico de tal manera que habrá una parte de la población a defender de otra que constituye una amenaza. De lo anterior, se deriva la segunda función: el racismo legitimará la muerte del otro, le otorgará validez con miras a sostener la pureza de la raza. En ese sentido, para Foucault respecto a la muerte del otro el racismo instaura una relación que ya no será de guerra o bélica sino de tipo biológica. La eliminación del otro ya no estará mediada por un elemento político sino biológico, no se dará muerte al otro en tanto que enemigo político sino en tanto que peligro biológico. No obstante, lo político sigue presente en la muerte pues debe ser entendida no solo como asesinato sino también como exclusión, rechazo, invisibilización o exposición al peligro de la muerte: una muerte política.

En suma, el racismo es el puente entre el poder y la muerte. Si el biopoder quiere ejercer el derecho de muerte soberano debe transitar por el racismo. De igual manera, si un poder de soberanía, en el ejercicio de su derecho de vida y muerte, pretende operar con las herramientas de la normalización debe pasar por el racismo. Es necesario que se tenga en cuenta que el racismo no se trata de un simple odio entre razas o grupos sociales, el racismo entraña 
un beneficio en términos biológicos para la propia especie en función de sus privilegios. Es decir, se ejerce el derecho de matar a través del racismo porque "significa el fortalecimiento biológico de uno mismo en tanto miembro de una raza o una población, en tanto elemento en una pluralidad unitaria y viviente" (Foucault, 2001: 233).

Si bien existe el prejuicio de que las categorías filosóficas son abstractas y lejanas a la realidad social, este concepto filosófico formulado en el siglo XX puede vincularse con fenómenos políticos contemporáneos; en ese sentido, la filosofía puede entenderse como matriz de análisis de la realidad fáctica. La actividad filosófica entraña una función importante que reside en su aplicabilidad sobre lo cotidiano. Cabe resaltar que no se trata de un determinismo o una relación causal entre los elementos en cuestión, sino que se pueden establecer lazos que permitan comprender hechos políticos. Aun cuando es importante elaborar herramientas conceptuales que respondan a un contexto específico contemporáneo, es válido recurrir a la tradición filosófica para extraer categorías de análisis que puedan dar luz sobre problemas políticos actuales.

Foucault realizó la labor, expuso dos casos en los que empleó el racismo para analizar la realidad política: el caso nazi y el caso soviético. En cuanto al caso nazi, el racismo fue política de Estado. El Tercer Reich usó de manera generalizada mecanismos disciplinarios y regularizadores y simultáneamente ejerció el poder soberano de muerte. Aunque ese derecho de muerte no era ejercido por una figura global sino por múltiples individuos, por todo el cuerpo social: desde las Schutzstaffel hasta los individuos que denunciaban a otro so pena de muerte. El Estado nazi tuvo un doble propósito: por una parte, el exterminio de las otras razas, un objetivo que suele catalogarse como el único y primordial del nazismo. Y por otro lado, la exposición de todo el cuerpo social a la muerte, es decir, ubicarlo en cercanías de su propia destrucción. Esa exposición, a juicio del autor, es la que permitirá que se consolide la raza nazi como superior por encima de las razas exterminadas o sometidas. En suma:

En los nazis se produjo la coincidencia de un biopoder generalizado con una dictadura a la vez absoluta y retransmitida a través de todo el cuerpo social por la enorme multiplicación del derecho de matar y la exposición a la muerte. Estamos frente a un Estado absolutamente racista, un Estado absolutamente asesino y un Estado absolutamente suicida (Foucault, 2001: 235). 
La conjunción de las tecnologías de poder ejecutadas al extremo llevaría al Estado nazi a concebir su autodestrucción encarnada en la denominada Solución Final, un plan genocida ideado para exterminar sistemáticamente la población judía pero que también contemplaba la destrucción de "las condiciones de vida del mismo pueblo alemán" (Foucault, 2001, 235). Así, el nazismo llevó al extremo la imbricación entre el derecho soberano de matar y la regularización biopolítica, una imbricación potencialmente peligrosa presente en la mecánica general de poder de los Estados modernos.

En cuanto al caso soviético, a juicio de Foucault el socialismo en todas sus modalidades o presentaciones es un tipo de racismo porque adoptó acríticamente, sin cuestionar sus fundamentos, el biopoder del Estado capitalista. El Estado socialista sin reparos sustanciales hizo uso del poder biopolítico sobre la vida, avaló estatización de lo biológico, y en ese sentido ejerció el derecho de muerte sobre los individuos. Ahora bien, el racismo no siempre fue empleado por el Estado socialista pues su uso dependía del propósito político al que sirviera:

Cada vez que [el socialismo] buscó el principio de la transformación en el nivel de los procesos económicos no necesitó el racismo, al menos en lo inmediato. En cambio, en todos los momentos en que (...) se vio obligado a insistir en el problema de la lucha, la lucha contra el enemigo, la eliminación del adversario dentro mismo de la sociedad capitalista; cuando se trató, por consiguiente, de pensar el enfrentamiento físico con el adversario de clase en la sociedad capitalista, el racismo resurgió, porque era la única manera que tenía un pensamiento socialista, que de todas formas estaba muy ligado a los temas del biopoder, de pensar la razón de matar al adversario (Foucault, 2001: 237).

Así pues, Foucault evidenció cómo es posible emplear el racismo como herramienta analítica para abordar problemas políticos concretos, pero posiblemente allí no se agota la utilidad del concepto en tanto podría ser útil para esclarecer problemas del universo político contemporáneo, aunque se requiera una actualización del concepto. En ese sentido, vale la pena preguntarse si la categoría es aún vigente y puede servir como "grilla de inteligibilidad" para analizar problemas políticos de la actualidad y facilitar su comprensión.

Aunque una respuesta satisfactoria a la pregunta anterior requeriría de una investigación minuciosa, lo cual excede los propósitos del presente artículo, 
a modo de conclusión preliminar es posible dar una respuesta afirmativa a dicho cuestionamiento. Por ejemplo, autores como Sheth (2011) exponen cómo el hecho que los musulmanes sean vistos como la nueva raza malvada, como una amenaza para Occidente evidencia la operatividad del racismo en el mundo contemporáneo. Asimismo, fenómenos políticos como la actual crisis de refugiados europea pueden leerse desde un enfoque racista. Desde 2015 un número elevado de personas ha llegado a Europa en busca de asilo a través del mar Mediterráneo y del sureste del continente, provenientes del occidente y sur de Asia así como del norte de África. De acuerdo a cifras de la Alta Comisión de las Naciones Unidas para Refugiados (ACNUR), la mayoría de refugiados que llegaron a Europa entre enero de 2015 y junio de 2016 provenían de Siria (33,1\%), Afganistán (17,4\%), Irak (10,6\%) y Nigeria $(5,3 \%)$ (ACNUR, 2016). En todo 2016 se estima que 63.920 niños llegaron sin compañía a Grecia, 28.223 a Italia, 6.447 a Bulgaria y 1.674 a España. El 92\% de los niños que cruzó el Mediterráneo en 2016 llegó sin compañía (ACNUR, UNICEF \& OIM, 2017).

Como respuesta a la crisis migratoria, la Unión Europea (UE) en tanto que organización supranacional implementó una serie de medidas encaminadas a hacer frente a la situación. Sin embargo, algunos Estados miembros no se acogieron íntegramente al marco normativo diseñado y asumieron posiciones contrarias a los lineamientos impartidos por la UE. Los casos de Eslovaquia donde su primer ministro Roberto Fico manifestó no estar dispuesto a aceptar refugiados que no sean cristianos porque su país es mayoritariamente cristiano (Guerlain, 2015); así como el caso de Hungría y su primer ministro Viktor Orban el cual expresó que la tradición europea está en riesgo porque la mayoría de migrantes son musulmanes (BBC, 2016), ilustran cómo el racismo de Estado sigue operando como instrumento soberano de la biopolítica, actúa como criterio de exclusión, marginación, rechazo y segregación en los Estados modernos. Aunque el análisis puede extenderse un poco más, como plantea Sheth (2011) al afirmar que el racismo crea divisiones ontológicas y recurre al plano moral, ya no al plano biológico, para legitimar dichas divisiones. La inclusión del ámbito moral como criterio de exclusión supone una actualización del concepto, lo que a su vez ratifica su actualidad y vigencia para el análisis de casos concretos en el mundo contemporáneo.

Ahora bien, las políticas migratorias que busca implementar el presidente estadounidense Donald Trump también son muestra de un racismo de Estado que sigue vigente y enquistado en las sociedades contemporáneas. 
Trump, a través de órdenes ejecutivas como Border Security and Immigration Enforcement Improvements (The White House, 2017a) y Protecting The Nation From Foreign Terrorist Entry Into The United States (The White House, 2017b) se propone, entre otras cosas, acelerar la expulsión de los indocumentados que se encuentren en territorio estadounidense priorizando la deportación de aquellas personas que hayan cometido un delito federal o sean sospechosas de haberlo cometido. Se parte del principio, a todas luces racista, según el cual "Aliens who illegally enter the United States without inspection or admission present a significant threat to national security and public safety" (The White House, 2017a).

De igual manera, las órdenes ejecutivas contemplan la posibilidad de construir un muro en la frontera entre México y Estados Unidos, dotar de competencia a las autoridades policiales locales para que puedan ejercer labores policivas migratorias, construir nuevos lugares de detención para los migrantes aprehendidos y retirar la financiación federal a aquellas ciudades y estados que no se acojan a los lineamientos presidenciales (Shear \& Nixon, 2017). Aunque las medidas ordenadas por Trump han encontrado oposición en instancias judiciales por lo que se ha dilatado su puesta en marcha, se trata de políticas racistas que de manera preocupante están logrando un alcance global y son respaldadas por amplios sectores de la población.

Para finalizar, cabe resaltar la importancia de volver la mirada a la obra de Foucault, estudiarla y analizarla con detenimiento, pues en ella es posible encontrar nuevas maneras de pensar y mirar los problemas filosóficos y políticos del presente en clave de enfoque crítico. La trascendencia y vigencia del pensamiento del filósofo francés también puede evaluarse en función de su aplicabilidad sobre lo cotidiano, sobre la realidad fáctica. En ese sentido, se espera que el presente artículo sea punto de partido para posteriores investigaciones sobre fenómenos políticos donde un grupo poblacional específico sea excluido y marginado por motivos raciales.

\section{REFERENCIAS BIBLIOGRÁFICAS}

ACNUR. (2016). Refugees \& migrants sea arrivals in Europe. Consultado en: https://data2.unhcr. org/en/documents/download/49921 Fecha de consulta: 25/02/2017.

ACNUR, UNICEF, \& OIM. (2017). Refugee and migrant children, including unaccompanied and separated children in the EU. Overview of trends in 2016. Consultado en: https://data2.unhcr.org/en/ documents/download/55971 Fecha de consulta: 30/08/2017. 
BBC. (2016). How is the migrant crisis dividing EU countries?. Consultado en: http://www.bbc.com/ news/world-europe-34278886 Fecha de consulta: 16/08/2017.

FOUCAULT, Michel. (1998). Historia de la sexualidad. La voluntad de saber. México D.F: Siglo XXI Editores.

FOUCAULT, Michel. (2001). Defender la sociedad. Buenos Aires: Fondo de Cultura Económica.

FOUCAULT, Michel. (2006). Seguridad, territorio y población. Buenos Aires: Fondo de Cultura Económica.

FOUCAULT, Michel. (2007). El poder psiquiátrico. Buenos Aires: Fondo de Cultura Económica. GUERLAIN, Pierre. (2015). Refugees and Responsibility in Europe and the U.S. http://www.huffingtonpost.com/pierre-guerlain/refugees-and-responsibili_b_8129130.html Fecha de consulta: 06/09/2017.

HALL, Lindsay. (2007). Death, Power, and the Body: A Bio-political Analysis of Death and Dying. Blackbusrg, VA: Virginia Polytechnic Institute and State University.

LÓPEZ, Cristina. (2013). "De la muerte en el contexto de las investigaciones sobre biopolítica de Michel Foucault". En: Revista Filosofía UIS, Vol. 12. No 1, págs. 67-84.

SHEAR, Michael., NIXON, Ron. (2017). New Trump Deportation Rules Allow Far More Expulsions. https://www.nytimes.com/2017/02/21/us/politics/dhs-immigration-trump.html. Fecha de consulta: 30/08/2017.

SHETH, Falguni. (2011). "The War on Terror and Ontopolitics: Concerns with Foucault's Account of Race, Power Sovereignty". En: Foucault Studies, Vol. 0. No 12, págs. 51-76.

THE WHITE HOUSE. (2017). Border Security and Immigration Enforcement Improvements. Washington D.C: The White House.

THE WHITE HOUSE. (2017). Protecting The Nation From Foreign Terrorist Entry Into The United States. Washington D.C: The White House. 